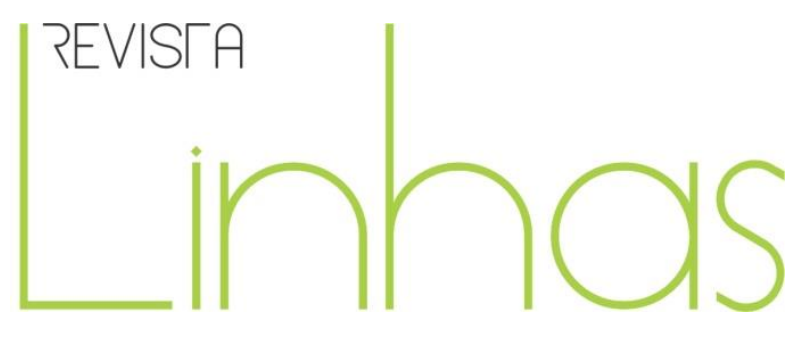

\title{
Resenha do livro "Cadernos Escolares e a escrita da história da educação matemática"
}

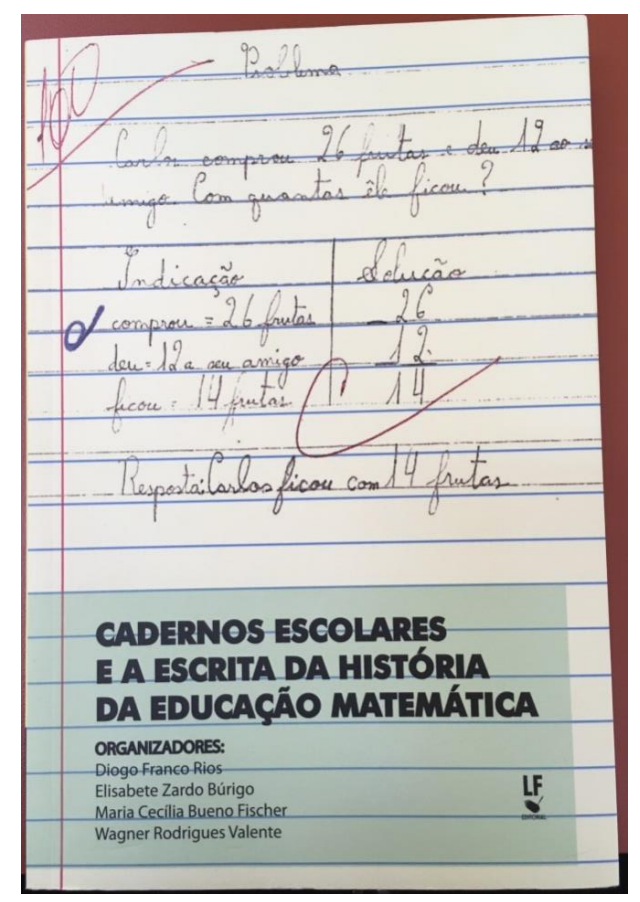

RIOS, Diogo Franco et al. (Orgs.). Cadernos Escolares e a escrita da história da educação matemática. São Paulo: Editora Livraria da Física, 2017.

\section{Bruna Frio Costa}

Universidade Federal de Pelotas - UFPel

Pelotas/RS - Brasil

brunafriocosta@gmail.com

\section{Para citar esta resenha:}

FRIO COSTA, Bruna. Resenha do livro "Cadernos Escolares e a escrita da história da educação matemática". Revista Linhas. Florianópolis, v. 19, n. 41, p. 379-381, set./dez. 2018. 
O livro Cadernos Escolares e a escrita da história da educação matemática foi organizado pelos professores Diogo Franco Rios (UFPel), Elisabete Zardo Búrigo (UFRGS), Maria Cecília Bueno Fischer (UFRGS) e Wagner Rodrigues Valente (UNIFESP). Foi publicado em 2017 pela editora Livraria Física (com apoio da Pro-Pesq/UFRGS e CAPES). Reúne trabalhos apresentados no XV Seminário Temático: cadernos escolares de alunos e professores e a história da educação matemática, 1890-1990, realizado na Universidade Federal de Pelotas (UFPel), na cidade de Pelotas/RS, entre os dias 29 e 30 de abril e $1^{\circ}$ de maio de 2017, sob a coordenação do GHEMAT (Grupo de Pesquisa de História da Educação Matemática no Brasil) e com apoio da CAPES e do CNPq. O referido grupo é responsável pelo projeto coletivo de pesquisa intitulado A Constituição dos Saberes Elementares Matemáticos: a aritmética, a geometria e o desenho do curso primário em perspectiva histórico-comparativa, 1890-1970, e tem como um de seus objetos de investigação os cadernos escolares com registros de aulas de matemática, foco do XV Seminário Temático do grupo. O GHEMAT reúne, desde 2006, grupos de pesquisa de cerca de vinte estados brasileiros e a realização de seminários temáticos é um de seus objetivos.

O livro é estruturado em quatro capítulos além da apresentação inicial dos organizadores. O primeiro capítulo é mais geral, na problematização dos cadernos como fontes e objetos de investigação, e os demais tratam fundamentalmente dos saberes matemáticos e, nesse caso, os cadernos escolares são analisados como portadores de saberes matemáticos de ensino e de formação.

O primeiro capítulo, Cadernos escolares como fonte e objeto da História da Educação é de autoria de Eliane Peres (FaE/UFPel) e é resultado da palestra proferida pela pesquisadora por ocasião da abertura do XV Seminário Temático (Pelotas, abril/maio, 2017). O objetivo do capítulo é contribuir para o debate acerca do caderno como fonte e/ou objeto de investigação nos estudos historiográficos. A autora salienta em seu texto que "talvez a matemática seja uma das disciplinas que melhor exemplifica os processos de aprendizagem de toda organização gráfica” (p. 21). Em suas considerações finais, destaca que não é suficiente apenas “juntar” cadernos, mas sim, construir formas de exploração desses documentos e ferramentas de análise.

O segundo capítulo, Cadernos de alunos com registros de aulas de matemáticas: 
textos e contextos, é de autoria de Barbara Winiarski Diesel Novaes (UTFPR), Luciane de Fatima Bertini (UNIFESP) e Moysés Gonçalves Siqueira Filho (UFES). Os autores definem dois objetivos no trabalho: i) identificar as opções teórico-metodológicas implícitas/explícitas nos referidos estudos; ii) identificar o movimento feito para a análise dos saberes elementares matemáticos presentes nos 25 cadernos utilizados por alunos dos primeiros anos escolares. Os autores concluem que o caderno é "muito mais de que um suporte para a escrita matemática" (p. 89). Afinal, segundo eles, a maneira como ocorrem as disposições gráficas altera o modo de pensar do aluno. Aqui, os cadernos são vistos como documentos que permitem a investigação da matemática presente no ensino e também na formação de professores.

O terceiro capítulo, Cadernos de professores que ensinaram matemática: contribuições para o estudo dos saberes a e para ensinar, éde autoria de Aparecida Rodrigues Silva Duarte (UNIVÁS/MG) e Rosimeire Aparecida Soares Borges (UNIVÁS/MG).No estudo foi adotado, como objeto de análise, textos que tratam de cadernos de professores com planejamento de aulas de matemática para o ensino primário. Buscou responder os seguintes questionamentos: i) quais saberes matemáticos foram mobilizados por estes professores no planejamento de suas aulas? ii) E quais as apropriações feitas por esses professores dos movimentos educacionais vigentes no período de sua elaboração? Tal estudo utilizou cinco cadernos de professores elaborados a partir da década de 1960. Usando termos como "matemática a ensinar" (números, operações fundamentais, tabuada) e "matemática para ensinar" (relacionado a atividades pedagógicas variadas como a resolução de problemas, situações-problema usando como exemplo o cotidiano), o capítulo apresenta reflexões importantes sobre a sobreposição de diferentes tempos e perspectivas pedagógicas nas/das práticas dos professores. As autoras concluem que "as práticas e propostas para o ensino de matemática são repletas de historicidade, visto que o passado se faz presente nas representações construídas sobre esse ensino" (p. 120). Concluem igualmente que os textos apresentados representam os primeiros passos na direção de se aprofundar pesquisas no âmbito da história da educação matemática no Brasil.

O quarto capítulo e último do livro, denominado fios e rastros nas análises históricas de cadernos com registros de aulas de matemática de normalistas e professores 
de normalistas, é da pesquisadora Circe Mary Silva da Silva (PUCRS). Neste capítulo, a autora se propõe a responder duas questões que caracteriza como "bem instigantes", a partir das discussões feitas durante do XV Seminário Temático: i) como os registros de aulas de matemática e de metodologia da matemática nos cadernos das escolas normais obtiveram saberes matemáticos para/e a ensinar; ii) Quais relações podem ser estabelecidas entre esses saberes e as práticas pedagógicas do ensino de matemática para normalistas? A autora chama atenção para os cuidados no trato com os cadernos, “objetos portadores de uma complexidade intrínseca de análise” (p. 126).

Este instigante livro, de interesse não só de historiadores da educação matemática, mas dos historiadores da educação em geral, contribui no avanço dos estudos sobre cadernos escolares, bem como permite novas e importantes reflexões para o desenvolvimento da investigação histórica, especialmente daquelas cujo foco é a educação matemática, o ensino, os dispositivos escolares, a cultura da escola dos anos iniciais. Indica possibilidades concretas de análise do registro das aulas de matemática a partir dos cadernos, no cruzamento com outras fontes documentais já incorporadas na escrita da história da educação matemática.

Recebido em: 07/02/2018

Aprovado em: 21/02/2018

Universidade do Estado de Santa Catarina - UDESC Programa de Pós-Graduação em Educação - PPGE Revista Linhas Volume 19 - Número 41 - Ano 2018 revistalinhas@gmail.com 